\footnotetext{
Cómo citar esta entrevista: Vergara Aguirre, A. (2019). Tomás González: el camino hacia la levedad. Estudios de Literatura Colombiana 45, pp. 187-197. DOI: https:// doi.org/10.17533/udea.elc.n45a11

andresvergaraa@udea.edu.co

Universidad de Antioquia, Colombia

Recibido: 15.02 .2019 Aprobado: 06.05.2019
}

Copyright: $\odot 2019$ Estudios de Literatura Colombiana. Este es un artículo de acceso abierto distribuido bajo los términos de la Licencia Creative Commons Atribución No comercial - Compartir igual 4.0 Internacional

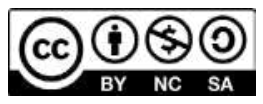

\section{Tomás GoNZÁlez: EL CAMINo HACIA LA LEVEDAD*}

\author{
Tomás González: The Way to Lightness
}

A Tomás González sería posible definirlo como un escritor prolífico, por todas sus novelas - Primero estaba el mar (1983), Para antes del olvido (1987), La historia de Horacio (2000), Los caballitos del diablo (2003), Abraham entre bandidos (2010), La luz difícil (2011), Temporal (2013), Niebla al mediodía (2015) y Las noches todas (2018)-, por sus tres libros de cuentos -El rey del Honka-Monka (1995), El lejano amor de los extraños (2013) y El expreso del sol (2016) - y por sus poemas, publicados en el volumen Manglares (1997). Sin embargo, también podríamos dudar de que ese término resulte pertinente para referirnos a él, porque después de su primera novela, parece que inició un camino en busca de la brevedad. Es más: aunque no haya certeza de que leyó las Seis propuestas para el próximo milenio, de Italo Calvino, tras leer su obra uno podría quedar convencido de que sí lo hizo, y que desde entonces acogió como su principio esencial en la escritura la búsqueda de la levedad, considerada esta "más como un valor que como un defecto", según lo advirtió en su conferencia el escritor italiano, en la cual hizo énfasis en que una de sus propias búsquedas como escritor había sido precisamente la levedad: "mi labor ha consistido las más de las veces en sustraer peso; he tratado de quitar peso a las figuras humanas, a los cuerpos celestes, a las ciudades; he tratado, sobre todo, de quitar peso a la estructura del relato y al lenguaje" (Calvino, 1994, p. 15).

Cuando ya estaba decidido a proponerle esta entrevista a Tomás González, comencé a indagar por su paradero, y algunos dijeron que el escritor todavía estaba radicado en Cachipay. Otros afirmaron que no, que ya vivía por el Oriente antioqueño, y algunos aconsejaron que lo buscara en El Peñol. Cuando al fin logramos contactarlo, él nos aclaró que sí vivió 
en esos lugares desde su retorno a Colombia, pero que al final ha regresado a Envigado, como en búsqueda del origen, para completar "un círculo que a mí mismo me ha sorprendido bastante", concluye.

Tomás, usted también es pintor. ¿Considera que sus relaciones con estas dos artes han ejercido una influencia importante en su producción literaria?

No, no soy pintor. Me llegan imágenes que podrían convertirse en pinturas, pero soy demasiado torpe con las manos y sería incapaz de plasmarlas. El que sí es pintor y además escribe es David, el protagonista de La luz difícil precisamente, la confusión en la introducción de la pregunta se debe a que se perciben tantas coincidencias entre el escritor y el personaje, que el lector puede terminar confundiéndolos]. Con David compartimos muchos de nuestros gustos. Las pinturas que más ha mirado David tal vez hayan sido las de Rembradt y las de Goya, e, igual que a mí, le gusta Bacon, Schiele, Ryder. Yo he mirado bastante el trabajo de Hokusai, el pintor del Monte Fuji y de La Ola [como también se le conoce, aunque su nombre original es La gran ola de Kanagawa], donde se plasma la intensidad de la vida cuando se pone en contacto cercano con la muerte. Quisiera tener La Ola en mi casa y también una de las mariamulatas de Grau, que David probablemente no conoce y dudo que le gusten, pues alcanzaría a notar en ellas el hiperesteticismo del resto de su obra. Como a mí me gustan las mariamulatas mismas, es decir, el animalito, no tengo tanto problema, y me sostengo firme en mi idea de comprarme un cuadrito de esos cuando tenga el modo. También me gustan algunas pinturas de Botero, que es antioqueño como yo y muy trabajador y parece pintar un mismo cuadro, aunque sea siempre distinto. Este pintor tampoco le gustaría a David. Botero tiene un cuadro de un ladrón con su bulto al hombro por los techos de tejas, que se me quedó para siempre en la memoria. También el de una mujer con sombrilla, caminando cerca del río por una arboleda tan gorda como ella. Es literatura. En su obra hay cosas bellas, lo malo es que pinta el trópico como los europeos y estadounidenses quieren vernos. Muchas moscas, muchos tipos de bigote y sombrero, muchas mujeres de mala vida. Una caricatura. También he mirado bastante a Gonzalo Ariza $\mathrm{y}$, más que tener un cuadro suyo, me gustaría que sus pinturas de la selva y del bosque húmedo de tierra templada hayan tenido alguna influencia en mi escritura. 
Como sobrino del maestro de Otraparte, tuvo la oportunidad de estar cerca de él en sus primeros años, y está presente en La historia de Horacio, a través de un personaje. ¿Compartiría con nosotros la evocación que puede hacer del Fernando González que conoció en su niñez?

Era un tío amable, como amables eran mi papá y los otros tíos. A sobrinos y nietos nos inspiraba mucho respeto, y así y todo le robábamos Pielrojas para fumárnoslos al escondido en el cafetal que había detrás de la casa. Estoy seguro de que Margarita y él se daban cuenta, pero no decían nada. Muy de vez en cuando los niños nos quedábamos oyéndolo hablar, como hipnotizados por los gestos y por la expresión de los ojos, pues no estábamos en capacidad de entender mucho de lo que decía. Lo que más nos interesaba era sentirnos orgullosos de él, chicanearle a los amigos por nuestro parentesco y ver la manera de robarle cigarrillos. De resto, nos movíamos por ahí como orangutanes jóvenes en los mandarinos o los zapotes, o jugábamos fútbol en una "manguita" (todavía no me acostumbro a la palabra, que no usaba desde hacía por lo menos cuarenta años) que había entre la casa principal y otra casa pequeña donde Fernando guardaba sus libros. Y a pesar de tanto haber estado trepado en los árboles con mis primos, que parecía como si no fuéramos a bajar y nos quedaríamos a vivir en ellos, y de tanto fútbol y de tanto lanzar trompos y jugar bolas o canicas, algo se me quedó de lo que decía Fernando, pues en el momento de escribir La Historia de Horacio me llegaron como del aire - fíjate cómo es la mente - frases suyas que seguramente yo traía desde entonces en la memoria. Otras las tomé directamente de sus libros.

\section{¿Cree que la cercanía con Fernando González pudo ejercer influencia en su decisión de estudiar filosofía y en su vocación como escritor?}

Es muy posible. Él tenía una personalidad fuerte y me inspiraba de niño, y aún me inspira, respeto y mucho afecto. Como vivía él era como valía la pena vivir, pensaba yo. Sin embargo, me interesaba la literatura más que la filosofía y si me matriculé en filosofía no fue tanto por Fernando, sino porque no había estudios específicos de literatura en aquella época, y los interesados estudiábamos filosofía. Claro que también me ha llamado la atención, y busco que mis narraciones se muevan o enmarquen dentro 
de esa admiración y ese asombro por el ser del Ser — ¿qué es lo que Es?, ¿qué carajos es Esto? - , admiración que le aparecía a Fernando con mucha intensidad y belleza en la mirada cuando hablaba o cuando caminaba por ahí con su boina y su bastón, observando el mundo. Allí tal vez esté su mayor influencia.

Si uno examina su trayectoria, advierte cierta reticencia suya a la figuración ante los medios de información, como si le rehuyera a la fama que ha conquistado su obra. ¿Qué piensa al respecto?

Mi obra ya es más conocida. Famosa, famosa, no es. Mi relación con la fama, en cualquier caso, sea propia o ajena, es ambigua o ambivalente, no sé cuál de las dos palabras ajusta mejor. Por un lado es el reconocimiento al trabajo y por otro es una distracción grande, canto de sirena que va descentrando al escritor y lo va minando. Considero que se escribe ante todo para explorar la realidad y recrearla con palabras, y solo por allá en tercer o cuarto lugar, para conseguir la fama o vender libros. Me gusta el reconocimiento, cómo no me va a gustar, y que se vendan y lean mis libros, pero trato de no trabajar con el objetivo de lograrlo. El lío es que la fama y la plata son adictivos. Fácil uno va dejando de escribir con el propósito aquel de explorar la realidad y el lenguaje, y cuando menos piensa está dedicado de tiempo completo a escribir para hacerse cada vez más rico y famoso.

¿Hay algunos escritores o algunas obras que hoy considere ejercieron más honda influencia en su escritura, o en su vida?

Te puedo decir cuáles me gustaron o impresionaron, pero no cómo podrían haber influido en mi trabajo. Cuando era joven leía tanto y en tal desorden que en esto de determinar las influencias se nos formaría un enredo serio. Que se me ocurran ahora están Lorca, García Márquez, Rulfo, D. H. Lawrence, Conrad, Lawrence Durrell, Witoldo Gombrowicz, Carrasquilla, Orwell, Osorio Lizarazo, Nicanor Parra, León de Greiff, Neruda, César Vallejo, Joyce, Cortázar, Carpentier, Arguedas, Shakespeare, La muerte de Artemio Cruz, Kafka, Dostoyevski, El sueño de las escalinatas, Tolstoi, José Asunción Silva, Poe, Hammett, Chandler, Baudelaire, Prévert, Pessoa y muchos otros. La lista parece no tener fin... A Faulkner lo leí mucho de joven y lo leo todavía. Es importantísimo por sus escritos y también por la manera de entender el 
trabajo literario en lo que tiene que ver con la plata y la fama. Faulkner hablaba, precisamente, de aquellos escritores que terminaban vendiendo el alma por una casa con piscina, que es como la venden los escritores de Estados Unidos.

Le repito la misma pregunta anterior, pero en el contexto nacional. ¿Hoy piensa en algún escritor o alguna obra de la literatura colombiana cuya lectura haya sido decisiva para usted?

Leyendo a todos los que cito antes y otros que no recuerdo ahora me formé como escritor. Todos ellos fueron decisivos. Si me pusiera a examinar mis escritos estoy seguro de que encontraría trazas de la influencia de Kafka, por ejemplo, que así de primeras no pensaría uno que la tenga. Más clara es la de Faulkner — con Palmeras salvajes, por ejemplo- o la de Conrad y Rulfo y García Márquez. En La muerte de Artemio Cruz, de Carlos Fuentes, encontré imágenes abrumadoramente hermosas y terribles. Ibargüengoitia también me gustó, por su humor suelto e irreverente. Los nombres siguen apareciendo.

Para responder con más disciplina a tu pregunta sobre la influencia de los colombianos, mencionaría a Tulio Bayer y su Carretera al mar, Álvarez Gardeazábal con sus Cóndores no entierran todos los días, Cepeda Samudio con La casa grande, y las obras de Silva, García Márquez, Carrasquilla y León de Greiff...

¿Cómo ve el panorama de la crítica literaria contemporánea en Colombia?

Por lo que me ha tocado, me he dado cuenta de que los críticos que pudiéramos llamar profesionales se cuentan con los dedos de una mano y nos quedan sobrando casi todos los dedos. La crítica importante, aquella que orienta al lector en sus lecturas y al escritor en su trabajo, la desempeñan en su mayor parte historiadores o economistas o sociólogos - lo hacen bastante bien, dicho sea de paso-, así como otros escritores. Entre los blogueros hay también críticos buenos. Los profesionales dejan qué desear. Parecen aficionados. Son subjetivos, vanidosos, cargan su ego y aciertan tanto como desaciertan. Parecen escritores. Prefiero la crítica de mis colegas, en realidad, pues no tienen que aparentar ser objetivos ni le tienen mucho miedo a desacertar, pues total ellos no son críticos. 


\section{¿Qué considera que es lo esencial a la hora de escribir?}

Trato de quitarme el miedo de meter la pata, de equivocarme, de escribir barrabasadas. Eso por un lado. Por el otro, yo diría que hay que tener una historia, dejando claro que la definición de lo que es una historia cambia de escritor en escritor. Es posible, incluso, que no sea indispensable tener historia alguna para empezar, y que sea mejor partir de una imagen, o de un perfume, o de un sonido, y dejar que la historia vaya apareciendo. Este es un camino válido que exige audacia y estar más que dispuesto a exponerse al fracaso, pero que podría también llevar a algún logro de los grandes. En mi caso, cuando tengo la tal historia y le pierdo el miedo a la barrabasada, soy capaz de contarla con alegría, como jugando, y de sorprenderme, como si yo mismo fuera mi primer lector.

En Primero estaba el mar aparece una atmósfera de fatalidad. ¿Es consciente de esa tensión entre la vida y la muerte que puede advertirse con cierta constancia en su producción literaria, desde aquella primera obra, e incluso en los poemas de su libro Manglares?

Durante muchos años no fui consciente de ese hecho. Hasta que un día me di cuenta. Y darse cuenta de estas cosas trae problemas, entre ellos el de quitarle espontaneidad al trabajo. Tengo una historia, por ejemplo. Como ya sé aquello de la tensión, pienso: "bueno, aquí está la historia que quiero contar. ¿Dónde tenemos en ella el encuentro entre la vida y la muerte, a ver?". De modo que el arco voltaico que antes se producía solo, ahora es inducido o podría ser inducido, y no hay nada qué hacerle, aparte de cuidar que no se note mucho al escribir. Dejar de saber es ya imposible. Pienso que conocer es siempre y sin excepciones mejor que ignorar, pero ese saber trae, como te digo, sus problemas, que uno debe resolver lo mejor que pueda y tratar de aprovechar en la escritura.

Usted ha mostrado versatilidad para moverse entre la novela, el cuento y la poesía. ¿Podría hablarnos de cómo percibe su experiencia en la producción de cada uno de estos géneros? ¿Por cuál género se siente más inclinado hoy? ¿Por qué?

Me siento a gusto con la novela corta y es lo que más he trabajado. Hay dos cosas, sin embargo, que quisiera hacer algún día y que son los dos extremos del asunto: novelas de más de quinientas páginas sin relleno 
y cuentos muy muy cortos que golpeen como knock outs o jaques mate no previstos, repentinos. En mi trabajo de ahora con novela, y como por variar y divertirme, estoy tratando de dejar el formato corto e intentar una novela un poco más larga, que se despliegue como los abanicos o las olas. No va a ser fácil, pues estoy convencido de que no existe historia que no se pueda contar bien en ciento cincuenta páginas. Tal vez el truco consista en gozar con las digresiones sin dejar que se pierda el hilo principal. También ayudarían las historias o tramas secundarias... Claro que de esa forma se diluye la contundencia... En fin, ya se verá. En cuento, sin embargo, sigo trabajando con historias más bien largas, que se me dan mejor que las cortas, creo yo, y en las que se gana o pierde por puntos, y no por knock out, para usar la comparación de Cortázar. Y de la poesía, mejor no hablar. Llega cuando le da la gana y así se va. Se parece a una de esas malezas bonitas que no se dejan domesticar. Por eso será que llaman así al Ojo de Poeta, la famosa enredadera. Traté de cultivarla en mi jardín de Chía y nunca logré que pegara, hasta que un día apareció sola en un rincón de la finca y empezó a crecer y a crecer, tanto que cada dos o tres meses me tocaba salir con escalera y podadoras para tratar de controlarla y evitar que nos ahogara a todos.

Esa versatilidad suya incluye la capacidad de borrar fronteras entre los géneros y las formas, que le permite pintar con palabras en la novela y en la poesía, e imprimirle poesía a su narrativa. Podemos mencionar La luz difícil o Temporal, por ejemplo. ¿Esa especie de sinestesia es intencional? ¿Qué nos dice al respecto?

Pienso que todo eso se da solo. Como se trata de una misma persona, sus experiencias se plasman en los diferentes géneros, pero son las mismas. A veces he tomado textos de las novelas y los pongo como poemas, es decir, acentúo, si puedo, su musicalidad, y los escribo en forma vertical. En el capítulo final de Primero estaba el mar, por ejemplo, se dice: "Y mientras sus mejillas se destejen — sus oídos se derrumban, su corazón se entrega a otros seres- el sol, el sol también fugaz, no ha dejado de brillar sobre otras vidas. Sobre los micos que saltan en las ramas. Sobre los toros que rumian sin cesar su propio peso. Sobre las gaviotas que restallan en el aire con su blanco estrépito. Sobre los hombres que comen mangos bajo el árbol” (González, 1997, p. 205). Eso mismo aparece en Manglares, así: 
CVI

El hígado se pierde como el humo

bajo un ramalazo de viento.

Los pulmones se hacen agua, tierra, viento.

Se pudre el corazón y se forman

libélulas, avispas, matorrales.

Se desmontan los oídos.

Se destejen las mejillas.

Son devueltos los cristales, son devueltos

los calcios y las sales

mientras soles, muchos soles,

no han dejado de brillar para otras vidas (González, 2018, p. 231).

Con esta comunicación entre mis obras me divierto, pero aspiro también a que le dé mayor cohesión al conjunto de libros.

Distintos autores han reconocido que independiente del género, al fin de cuentas el escritor siempre escribe sobre sí mismo, pero que se camufla en los personajes. En sus cuentos y en sus novelas, al leer ciertos personajes uno siente que encarnan al autor, y que usted no ha pretendido camuflarse. Cuéntenos un poco de su experiencia de narrar su historia personal y familiar en algunas de sus obras, que ya se hace evidente en la novela Primero estaba el mar y en los cuentos de El rey de Honka-Monka.

Para que mi historia ruede sin problemas aprovecho todo lo que tengo a mi disposición, incluidos yo mismo y mis circunstancias. Pero no lo hago por hablar de mí o porque tenga intenciones autobiográficas. Tomo lo que necesito de lo que he vivido tanto como de aquello que he oído o visto o incluso leído o imaginado. Lo importante es que la historia fluya y alcance tanta fuerza, belleza y resonancia como me sea posible. En $\mathrm{La}$ luz difícil, por ejemplo, lo que podríamos llamar la infraestructura de la novela lo tomé de aquello que fue la infraestructura de mi vida durante una larga época, primero en Nueva York y luego en Cachipay. El apartamento del East Village, con Cristóbal y el cementerio, es nuestro apartamento de esos años. Sara se parece bastante a Dora. Mi hijo Lucas se parece a todos los hijos de David, quien a su vez se parece mucho al mí mismo de esa época. Pero todo esto lo hice porque me ayudaba a que la historia fluyera y se anclara bien en Lo Real y no por querer pasar como de contrabando 
mi autobiografía. El libro que sí tiene intenciones autobiográficas es el de poemas, Manglares. Allí, con el desorden propio de la memoria, consigno eventos significativos de mi vida, desde la muerte de mis hermanos hasta las clases de filosofía de la Nacional.

\section{¿Qué le gusta leer a Tomás González en la actualidad?}

Últimamente la música me está quitando el tiempo de lectura. Me pongo a explorar los servicios de música y ahí se me va el tiempo que antes dedicaba a leer. Esta situación lleva algo así como un año. Hice una pausa para leer El ruido de las cosas al caer, que me gustó, y voy a hacer otra para leer La Perra, que me han recomendado mucho. No estoy muy al día en literatura colombiana y pienso dedicarme a eso un buen rato, si la música me deja, pues estamos pasando por un momento importante. $E l$ desbarrancadero y Los Ejércitos están en la lista de lecturas pendientes. De Rosero aún no he leído nada, y es una lástima, pues me gusta la manera como trabaja y lo que dice en sus entrevistas. De Fernando Vallejo solamente conozco La virgen de los sicarios, que leí con interés y también me pareció bien escrita. Y antes de que la música me hiciera olvidar mi querido Kindle, venía con bastante entusiasmado con Melville, que es un gran filósofo, un gran narrador y un gran poeta, además de decentísimo ser humano. Tengo entonces por un lado a Melville y, por el otro, la posibilidad de encontrar joyas poco conocidas de Benny Moré o de Chuck Berry. La situación está difícil.

\section{Olvidémonos por un momento del escritor para preguntarle al lector: ¿cómo ve el panorama literario contemporáneo en Colombia?}

Se está escribiendo mucho y se está tratando de alcanzar la excelencia. La cantidad de obras y de buenos escritores que hay en la actualidad no tiene precedentes en la literatura colombiana. Tenemos mucho para contar y hay mucha gente que quiere contarlo y tiene la solvencia para hacerlo muy bien. Tal vez vayamos hacia un segundo boom, en Colombia y en América Latina. Una segunda ola, después del reflujo que se produjo luego del primer boom. En Colombia la presencia de García Márquez ha sido esencial en todo esto, pues subió al máximo el nivel de calidad y exigencia y debilitó así el espíritu de autocomplacencia y medianía. 
Al pensarlo hoy, en retrospectiva, ¿qué cree que significó para usted la experiencia de vivir en Nueva York? ¿No es demasiado el contraste de pasar de una ciudad como esa a la calma de los sitios en los que ha vivido desde su regreso a Colombia?

No creo que haya ciudad que se compare con Nueva York. Ni siquiera Pereira, ni siquiera Cali. Regresar a una ciudad habría sido una pérdida. En cambio, volver al campo fue algo mágico y me tuvo medio alucinado algo así como dos años. Pura ganancia. Disfrutaba de los carritos con peroles brillantes de hierro martillado que pasaban por la carretera. Disfrutaba de los tres colores de la bandera en las casas campesinas de la vereda La Balsa. De las campanas de los vendedores de gas. De las grabaciones de los recolectores de chatarra, a la vez granulosas y a gran volumen. De las rosas en los antejardines. De las plazas de mercado y de su alegría como de colcha de retazos. Del ruido de fondo o transfondo, que era por fin en español y no en inglés. Sonaba, por ejemplo, Juan Charrasqueado a las diez de la mañana en algún campo de tejo cercano y me sentía contento de estar otra vez en mi país. Ya llegaría después el momento de sentir la ofuscación por la música ruidosa de las canchas de tejo, pero por lo pronto hasta eso me gustaba.

\section{¿A qué aspira Tomás González hoy?}

Aspiro a lo mismo de siempre, es decir, a escribir cada vez mejor, a disfrutar cada vez más de la escritura.

Finalmente, como una manera dehacerle ecoa esa idea de circularidad planteada por el escritor, dejemos que sea el mismo Tomás quien nos hable de su periplo Colombia, desde que volvió de Nueva York:

Vivo en Envigado, en la loma de El Esmeraldal. De exactamente este mismo sitio me fui a principios de los ochenta y regresé hace un mes, completando así un círculo que a mí mismo me ha sorprendido bastante. Había vivido antes en Cachipay, como diez años, y de allí me fui para El Peñol, donde viví como dos. Hace un mes apenas me vine para una finca metida entre torres de apartamentos, en una casita bonita, de bahareque, como me gustan, al lado de la de mi hermano Alberto, en el Envigado de mis antepasados. Hay una perrita labrador muy anciana que cuando no está saludando o comiendo, está durmiendo. Color chocolate, cejas muy canosas. Y hay un gato que tiene las mismas pintas y hasta la misma personalidad de mi querido y finado gato Cristóbal, y que se llama Romeo. 
Así describe Tomás González su ámbito de hoy, como si quisiera confirmarnos esa idea que nos deja el recorrido por su obra: que es un escritor en búsqueda de la levedad.

\section{Referencias bibliográficas}

Calvino, I. (1994). Seis propuestas para el próximo Mileno. Madrid: Siruela.

González, T. (2013). Manglares. Bogotá: Alfaguara.

González, T. (1997). Primero estaba el mar [1983]. P. Bogotá: Seix Barral. 